Article

\title{
Anti-Graffiti Behavior of Oleo/Hydrophobic Nano-Filled Coatings Applied on Natural Stone Materials
}

\author{
Mariateresa Lettieri ${ }^{1}\left(\mathbb{D}\right.$, Maurizio Masieri $^{1}$, Mariachiara Pipoli ${ }^{2}$, Alessandra Morelli ${ }^{2}$ and \\ Mariaenrica Frigione $2, *$ (D) \\ 1 Istituto di Scienze del Patrimonio Culturale, CNR-ISPC, Prov.le Lecce-Monteroni, 73100 Lecce, Italy; \\ mariateresa.lettieri@cnr.it (M.L.); maurizio.masieri@cnr.it (M.M.) \\ 2 Department of Engineering for Innovation, University of Salento, 73100 Lecce, Italy; \\ mchiara.pipoli@libero.it (M.P.); alessmorel@tiscali.it (A.M.) \\ * Correspondence: mariaenrica.frigione@unisalento.it; Tel.: +39-0832-297-215
}

Received: 7 October 2019; Accepted: 5 November 2019; Published: 7 November 2019

\begin{abstract}
In recent years, graffiti writings are increasingly regarded as a form of art. However, their presence on historic building remains a vandalism and different strategies have been developed to clean or, preferably, protect the surfaces. In this study, an experimental nano-filled coating, based on fluorine resin containing $\mathrm{SiO}_{2}$ nano-particles, and two commercial products have been applied on compact and porous calcareous stones, representative of building materials used in the Mediterranean basin, and their anti-graffiti ability has been analyzed. All the tested experimental and commercial coatings exhibited high hydrophobicity and oleophobicity, thus meeting one of the basic requirements for anti-graffiti systems. The effects of staining by acrylic blu-colored spray paint and felt-tip marker were, then, assessed; the properties of the treated stone surfaces after cleaning by acetone were also investigated. Visual observations, contact angle measurements and color evaluations were performed to this aim. It was found that the protective coatings facilitated the spray paint removal; however high oleophobicity or paint repellence did not guarantee a complete cleaning. The stain from the felt-tip marker was confirmed to be extremely difficult to remove. The cleaning with a neat unconfined solvent promoted the movement of the applied polymers (and likely of the paint, as well) in the porous structure of the stone substrate.
\end{abstract}

Keywords: hydrophobic treatments; oleophobicity; nano-particles; stone protection; anti-graffiti coatings; chemical cleaning; acrylic-based paints; felt-tip markers

\section{Introduction}

Over the last few years, holistic approaches are trying to tackle the global graffiti phenomenon [1]. Any proposed solution is shared with all the involved stakeholders, including those who manage graffiti or utilize street art for city regeneration. The current studies are addressing not only to the graffiti removal, but also to the knowledge and protection of the street art murals [2-4].

However, graffiti on building façades, especially those with a cultural and historical value, still remain a vandalism [5]. Several strategies are used to either remove these graffiti or protect the surfaces against their harmful effects [6].

Mechanical, chemical or laser techniques are typically employed for the cleaning procedures [7-11]; biocleaning methods have been also proposed [12,13]. Graffiti removal is expensive and, in some cases, may cause stone damage due to chemical contamination, by-products formation and physical changes. Therefore, preventive actions are preferred, especially on artifacts of historical and artistic relevance. 
To this aim, coatings acting as anti-graffiti barrier have been developed in the last years and many products are nowadays commercially available. The anti-graffiti products can be grouped into three main classes: sacrificial, semi-permanent and permanent [14]. The sacrificial coatings are removed during the cleaning process and they need to be renewed; the semi-permanent systems endure a few cleaning cycles (normally, not more than two or three); the permanent products are not taken away during the cleaning process and they are able to withstand several cleaning cycles. The formulations suitable for application on stone materials [15-23] are mainly based on waxes, fluorinated polymers, silicon resins or polyurethanes; more recently, coatings incorporating nano-particles [17,24-26], organic-inorganic hybrid products [27-29] and surface functionalization [30] have been investigated as potential anti-graffiti systems. The fundamental characteristics that these treatments must display are: transparency, permeability to water vapor, durability under outdoor conditions. In addition, non-wettable coatings are preferred to enable the treated surfaces to repel paints and other staining agents [31].

Wetting is the ability of a liquid to maintain contact with a solid surface; the balance between the intermolecular interactions of adhesive type (liquid to surface) and cohesive type (liquid to liquid) controls this feature. Wettability of a solid surface can be described by the contact angles and sliding angle; models (Young, Wenzel, Cassie-Baxter) have been developed to illustrate the wetting phenomena on surfaces $[32,33]$. The decrease of the wettability corresponds to an increase in liquid-phobicity. Regarding water, a surface is called hydrophobic when water drops on it exhibit contact angles greater than $90^{\circ}$. When the contact angles are $150^{\circ}$ or higher, the surface is classified as superhydrophobic. Despite their high level properties, superhydrophobic surfaces have low mechanical wear resistance and poor long-term durability, therefore, their utilization in real applications is still limited [33-35]. Water-repellency is achieved in super-hydrophobic surfaces with water contact angle hysteresis $<10^{\circ}$, that is a low difference between the advancing and receding contact angles. In these conditions, a water droplet can move with little applied force and easily rolls off from the surface [36]. Similar considerations are applied to oleo-phobic/-repellent surfaces [37].

Several methods have been used to design and produce non-wettable stone surfaces, often bioinspired to either plants or insects surfaces. The most common procedures include the application of polymer coatings able to reduce the surface tension of the substrate, sol-gel processes and controlled nano-particle embedding into polymer matrices [29].

Hydrophobicity and oleophobicity are assumed as basic properties to provide protection against graffiti [38-46]; however, the related actual anti-graffiti action is taken for granted and few are the studies where this property has been proved in oleo/hydrophobic coatings applied on stone substrates $[43,45]$. Starting from these issues, an experimental work, aimed at investigating the performance of oleo/hydrophobic coatings and their behavior as anti-graffiti systems applied on building stone materials, has been undertaken. The present study is a part of a wide research on products suitable for superficial protection of stone materials.

Three products have been applied on both compact and porous calcareous stones representative of building materials used in the Mediterranean basin. Two of the used products are already commercially available and are suggested to provide water and anti-graffiti protection to stone surfaces. An experimental nano-filled system, based on fluorine resin containing $\mathrm{SiO}_{2}$ nano-particles, has been also investigated.

Blu-colored spray paint and felt-tip marker were used as staining agents. Traditional and easy-to-apply methods usually used by restores and professionals were chosen for the stain removal. Cleaning procedures by warm water and, subsequently, by acetone, were applied to the stained stone surfaces. The properties of the stone surfaces were, then, analyzed by visual observations, contact angle measurements and color evaluations, on stained and neat surfaces, as well as after the paint removal. The percentage of residual stain and the efficacy of the cleaning procedures, in comparison with the unprotected stone surfaces, were used to measure the paint removal. 


\section{Materials and Methods}

\subsection{Protective Products, Stone Materials, and Staining Agents}

An experimental formulation and, for comparison purposes, two commercial products were investigated.

The experimental product, hereinafter nanoF, is a water-based fluorine resin (12.7 wt.\%) containing $\mathrm{SiO}_{2}$ nano-particles (10 wt.\%), 40-50 nm in dimensions (supplied by Kimia S.p.A., Perugia, Italy); nanoF has density of $1.04 \mathrm{~g} / \mathrm{cm}^{3}$ and $\mathrm{pH}$ between 7 and 8; the viscosity, similar to those of the commercial systems, was appropriate for the application by brush [47]. The first commercial product, F (trade mark Fluoline PE, supplied by C.T.S. S.r.l., Altavilla Vicentina, Italy), is an aqueous dispersion of fluoropolyethers (10 wt.\%); this system was selected to compare the experimental nano-filled formulation to a unfilled chemically similar product already on the market (nanoF and $\mathrm{F}$ are, indeed, both fluorine-based). The second commercial system, hereinafter SW (trade mark Kimistone DEFENDER, supplied by Kimia S.p.A., Italy), consisting of a mixture of organic silicon compounds and microcrystalline waxes in water solution; SW was included in the study because it belongs to a family of products, i.e., the silicon-based, widely and successfully used in the field of stone conservation. According to the technical sheets, both the commercial systems are able to provide a reversible and hydrophobic coating on the treated surfaces, with dirt-repellent and anti-graffiti properties. Additional information about the protective systems has been reported in a previous study [47].

The three protective products were tested on two natural calcareous stone materials, representative of construction materials used for historic and civil buildings in many countries in the Mediterranean basin. A highly porous calcarenite (PS), named "Lecce stone", and a compact limestone (CS), known as "Trani stone", were used.

The principal constituent of "Lecce stone" is calcite (93\%-97\% [48]); in this material, very small quantities of clay, phosphates and other non-carbonate minerals are also present $[49,50]$. Petrographically, "Lecce stone" is a packstone [51], made of microfossils and fossil remains within a groundmass of fine calcareous detritus (Figure 1a). The used samples exhibited a porosity of $39 \%$, with pore sizes mainly between 0.5 and $6 \mu \mathrm{m}$ (Figure $1 \mathrm{~b}$ ), as analyzed by mercury-intrusion porosimetry (MIP) [52].

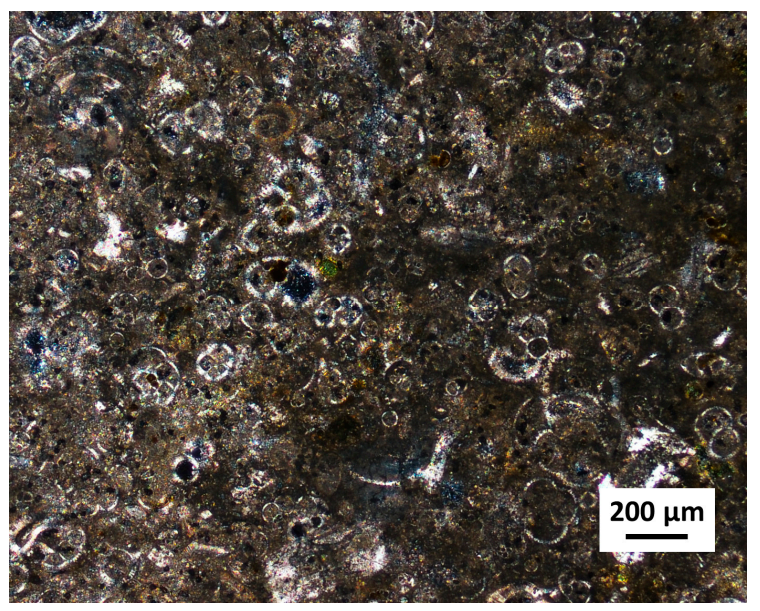

(a)

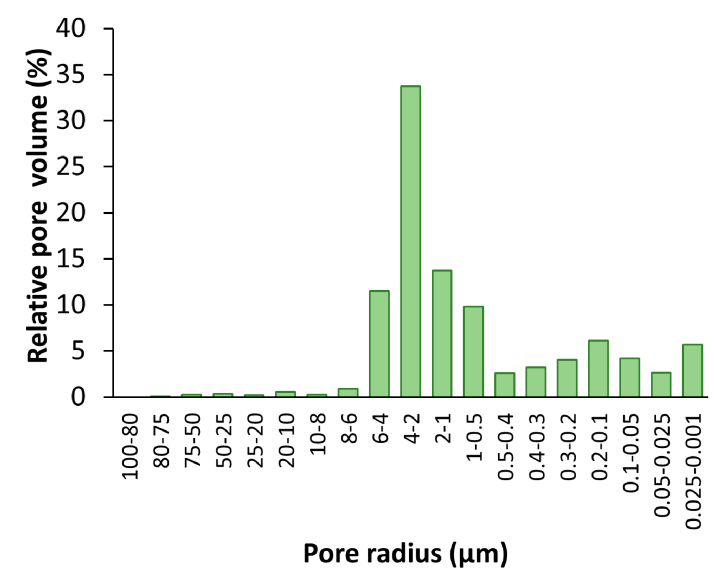

(b)

Figure 1. Lecce stone: (a) image taken on thin sections through optical microscope (Eclipse LV 100 PL, Nikon, Tokyo, Japan) in transmitted light; (b) pore-size distribution curve.

"Trani stone" is mainly composed of calcite (>95\% [36]), and low amounts of clay minerals and iron oxides [33]. "Trani stone" is a packstone [51] made of calcareous detritic grains, very well cemented 
by a crystalline cement filling the interparticle porosity (Figure 2a). The open porosity, measured by MIP, was very low (2\%); the pore size was mainly between 0.025 and $0.001 \mu \mathrm{m}$ (Figure 2b).

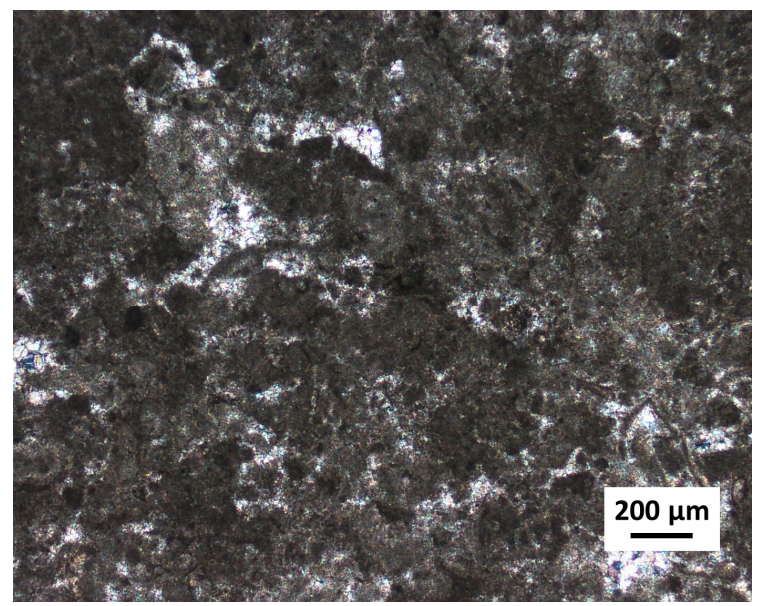

(a)

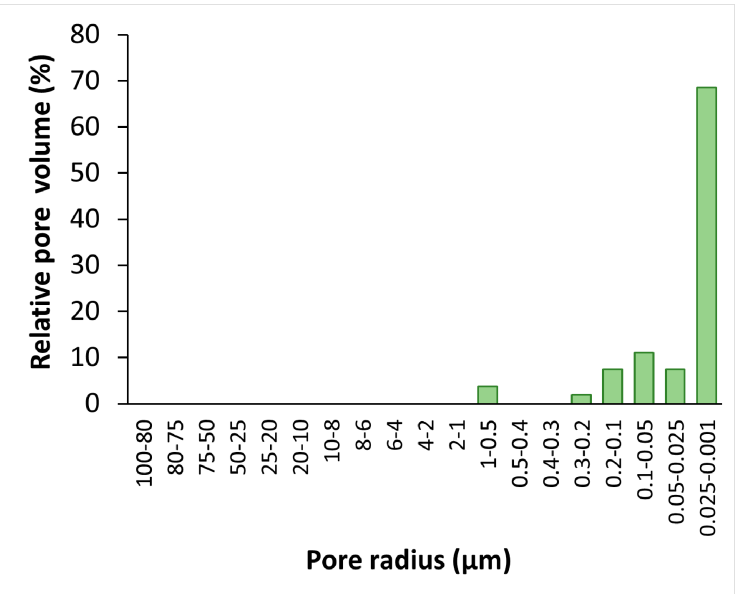

(b)

Figure 2. Trani stone: (a) image taken on thin sections through optical microscope (Eclipse LV 100 PL, Nikon, Tokyo, Japan) in transmitted light; (b) pore-size distribution curve.

Two staining agents were applied to test the protective action of each coating applied on the stones, i.e., (1) a commercial acrylic spray paint (Cilvani RAL by Cilvani S.r.l., Caivano, Italy), blu-colored (RAL code 5015), provided in a pressurized can; (2) a water-based acrylic paint marker (POSCA by UNI Mitsubishi pencil, Tokyo, Japan), blu-colored (RAL code 5005), having a bullet tip 1.8-2.5 mm wide (PC-5M).

\subsection{Stone Specimens}

Prismatic specimens of PS and CS stones, with dimensions of $5 \mathrm{~cm} \times 5 \mathrm{~cm} \times 1 \mathrm{~cm}$, were cut by a saw from quarry blocks. According to the UNI10921 standard protocol [53], the samples were smoothed with abrasive paper (180-grit silicon carbide), cleaned with a soft brush and washed with deionized water in order to remove dust deposits. The stone specimens were completely dried in oven at $60^{\circ} \mathrm{C}$, until the dry weight was achieved, and stored in a desiccator with silica gel (relative humidity (R.H.) $=15 \%$ ) at $23 \pm 2{ }^{\circ} \mathrm{C}$. Before the application of each protective product, the stone specimens were conditioned in equilibrium with the surrounding environment $\left(24 \mathrm{~h}\right.$ in the laboratory, at $23 \pm 2{ }^{\circ} \mathrm{C}$ and $45 \% \pm 5 \%$ R.H.).

The treatments were applied by brush on 3 sample surfaces $(5 \mathrm{~cm} \times 5 \mathrm{~cm})$ for each product.

For F and SW, the amounts of product suggested in the technical sheets were applied. Preliminary tests were used to verify the optimal amount of nanoF to effectively treat the two stone materials [47]. Following the minimum intervention criteria, the quantities suitable to obtain highly hydrophobic surfaces along with minimal color changes were identified. For all the products, greater amounts were necessary to guarantee good performances in the highly porous stone (PS).

The actual amount of the applied product was evaluated by weighting the specimens before and after the treatment. After the application of the products, all the specimens were kept in the laboratory at $23 \pm 2{ }^{\circ} \mathrm{C}$ and $45 \% \pm 5 \%$ R.H. for 30 days; then, they were dried in oven at $40{ }^{\circ} \mathrm{C}$ until the weight stabilization was achieved, the stabilization being controlled by periodical weight measurements. The treatments' harmlessness, assessed in terms of surface color variations and reduction in water vapor permeability, was proved in a previous study [47]; the main results are summarized in Table 1. 
Table 1. Amount of applied product, color change $\left(\Delta E_{\mathrm{ab}}^{*}\right)$ and variation of water vapor permeability $(\Delta P)$ evaluated after the protective treatment [47].

\begin{tabular}{ccccc}
\hline Stone Substrate & Product & Applied Amount $\left(\mathrm{g} / \mathbf{m}^{\mathbf{2}}\right)$ & $\boldsymbol{\Delta} E_{\mathbf{a b}}^{*}(\mathbf{C I E L A B}$ unit $)$ & $\boldsymbol{\Delta} \boldsymbol{P}(\mathbf{\%})$ \\
\hline \multirow{2}{*}{ CS } & nanoF & 58 & 1.72 & +15 \\
& $\mathrm{~F}$ & 60 & 2.50 & -5 \\
& $\mathrm{SW}$ & 109 & 2.56 & -38 \\
\hline \multirow{2}{*}{ PS } & nanoF & 155 & 1.38 & +14 \\
& $\mathrm{~F}$ & 160 & 3.97 & -6 \\
& $\mathrm{SW}$ & 313 & 3.51 & -51 \\
\hline
\end{tabular}

The staining of the surfaces was performed 2 months after the application of the protective coatings, as detailed in Section 2.3.

During the preparation of the specimens, their subsequent treatments and relative tests, the environmental conditions were monitored by means of a thermo-hygrometer (Mod. EMR812HGN, Oregon Scientific, Hong Kong, China). This instrument is able to collect temperature data from -50 to $70{ }^{\circ} \mathrm{C}$ (with resolution of $0.1{ }^{\circ} \mathrm{C}$ ) and relative humidity data in the range $2 \%-98 \%$ (with resolution of $\pm 1 \%$ ). All weight measurements were registered using an analytical balance (Model BP 2215, Sartorius, Goettingen, Germany) with an accuracy of $\pm 0.1 \mathrm{mg}$.

All the procedures carried out on the stone samples are illustrated in Figure 3.

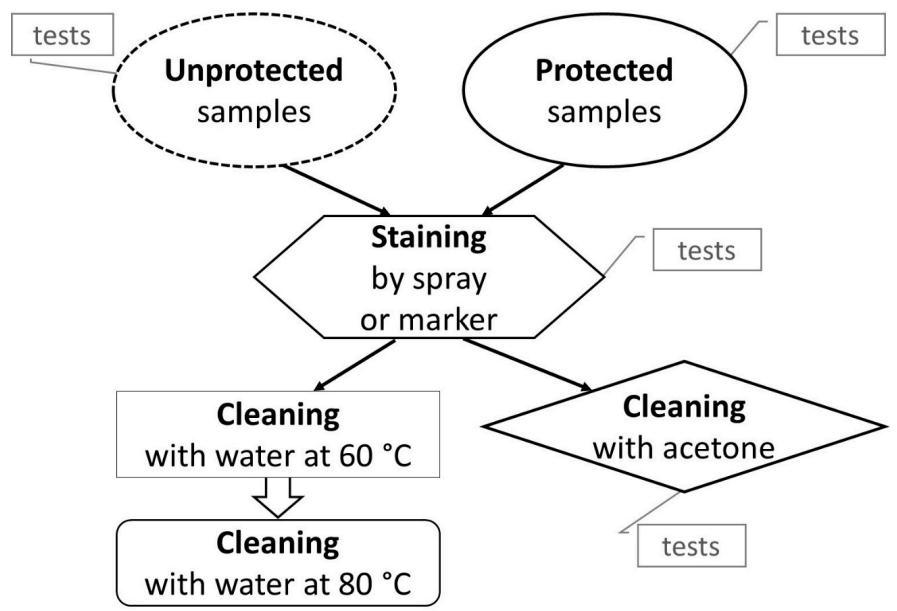

Figure 3. Experimental procedures.

\subsection{Staining Methods and Removal Procedures}

\subsubsection{Spray Paint}

The staining with the spray paint was carried out on untreated and protected stone samples, conditioned in equilibrium with the surrounding environment $\left(24 \mathrm{~h}\right.$ in the laboratory, at $23 \pm 2{ }^{\circ} \mathrm{C}$ and $50 \% \pm 5 \%$ R.H.). Two coats of paint were sprayed on specimens placed on a $45^{\circ}$ tilted surface (Figure 4a). The distance between the sample surface and the nebulizer was about $15 \mathrm{~cm}$. In order to limit the deposition of paint to an area of $1.5 \mathrm{~cm} \times 5 \mathrm{~cm}$, the staining was performed with the aid of a stencil and the lateral sides of the specimens were protected with a polyester (PET) film. 


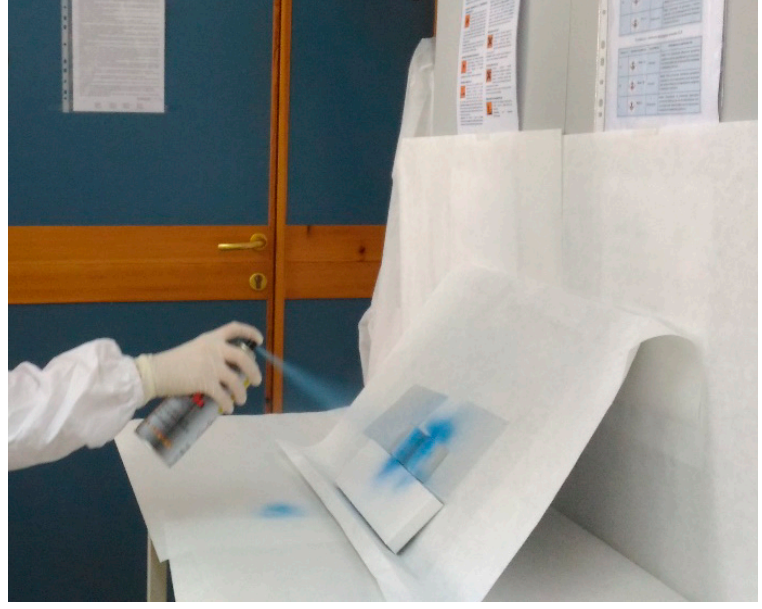

(a)

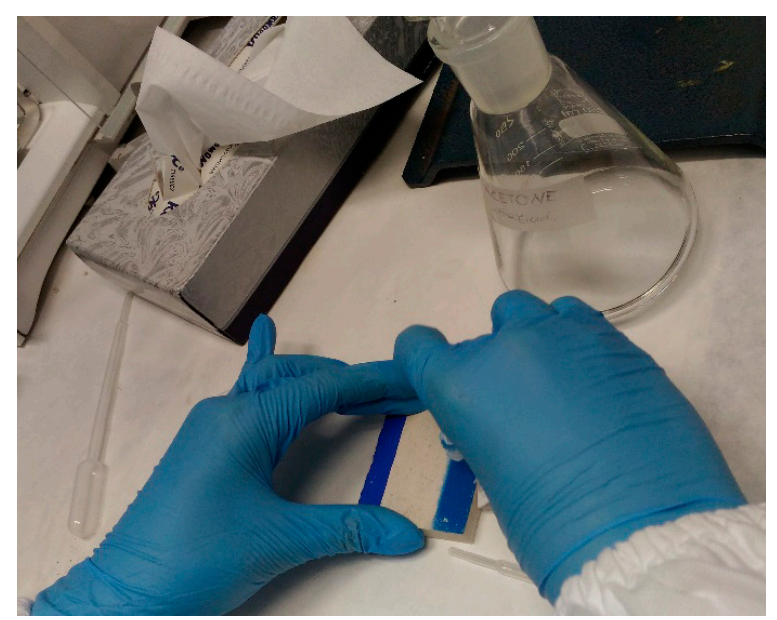

(b)

Figure 4. Staining by spray paint (a) and removal with acetone (b).

After the application of the paint, the samples were stored for 2 days in the laboratory at $23 \pm 2{ }^{\circ} \mathrm{C}$ and $50 \% \pm 5 \%$ R.H. The removal procedures were performed 20 days after the staining. Starting from the data reported in the technical sheet of the SW product, a first cleaning with warm water (at $60^{\circ} \mathrm{C}$ and next at $80^{\circ} \mathrm{C}$ ) and paper towels, was firstly attempted on testing areas. Since this method resulted totally ineffective, it was no more applied to the stained specimens and its effects were not further investigated. Then, following the recommendation reported in the international code [54], cleaning with an organic solvent was tried. Acetone was selected because it is (alone or in mixture with other organic solvents) a traditional solvent for the cleaning of stone materials affected by graffiti [6]; it has been successfully used to remove acrylic paints, as reported in previous studies [9,55]. Acetone analytical grade, supplied by Carlo Erba Reagents (Val de Reuil, France) was used. For each sample, a wet paper towel was rubbed across the stained area (Figure $4 \mathrm{~b}$ ) for 25 complete back and forth cycles [54]; the towel was dunked in acetone every 5 cycles.

\subsubsection{Felt-Tip Paint Marker}

The staining with the felt-tip marker was performed on untreated and protected stone samples conditioned in equilibrium with the surrounding environment $\left(24 \mathrm{~h}\right.$ in the laboratory, at $23 \pm 2{ }^{\circ} \mathrm{C}$ and $50 \% \pm 5 \%$ R.H.). The paint was applied to an area of approximately $1.5 \mathrm{~cm} \times 5 \mathrm{~cm}$ in the same specimens stained with the spray paint, but in a different zone (Figure 5).

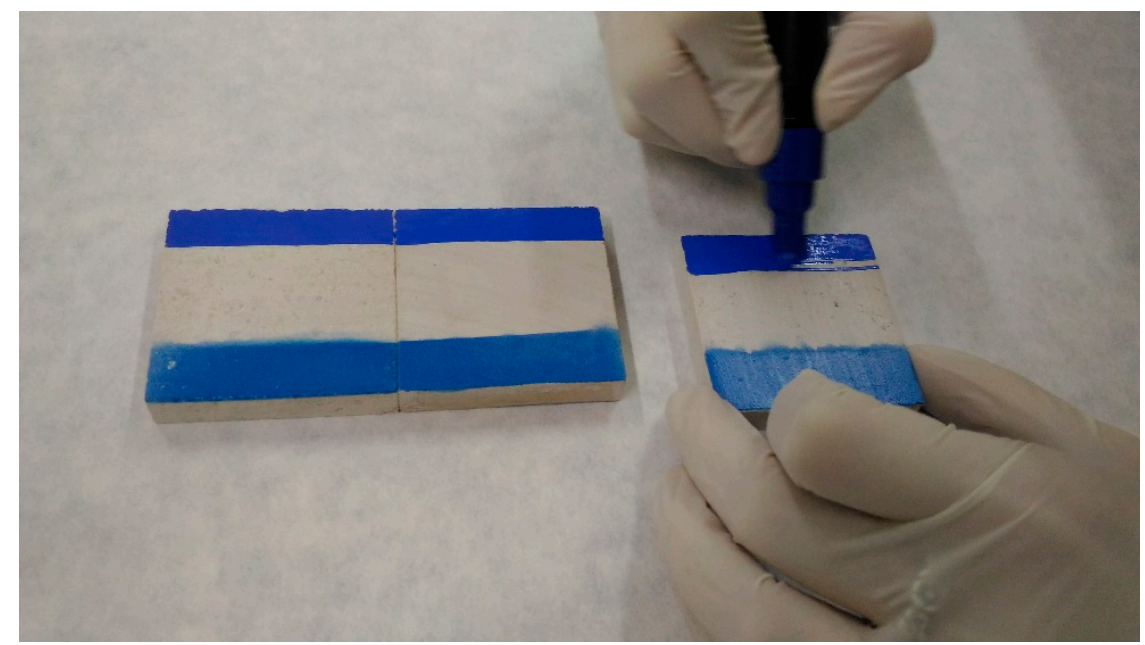

Figure 5. Staining by felt-tip marker. 
The samples were, then, kept in the laboratory conditions $\left(23 \pm 2{ }^{\circ} \mathrm{C}\right.$ and $50 \% \pm 5 \%$ R.H) for 2 days. The same removal procedures used to clean the samples stained with the spray paint (described in Section 2.3.1) were carried out 18 days after the staining with the marker.

\subsection{Analytical Investigations}

In order to evaluate hydrophobicity and oleophobicity of the stone surfaces, static contact angle measurements were performed before and after the coatings' application. A Costech apparatus was used to deposit micro-drops of the wetting liquid on the stone surfaces. The shape of the drop was recorded with a camera and the related contact angle was calculated by means of the "anglometer 2.0" software (Costech). To assure the reproducibility of the test, the image of each drop was acquired $15 \mathrm{~s}$ after its deposition.

The water-stone contact angles were measured on 30 different positions of the surface of each specimen using deionized water as wetting liquid, according to the European standard [56]. A commercial olive oil (purchased from a local market) was used to determine the oil-stone static contact angle, following a procedure already proposed in other studies [57-59]; 5 measurements were performed on each sample and the results were averaged.

For the unprotected Lecce stone (PS), the absorption of wetting liquids is rapid because of the high stone porosity. Consequently, during the test, the drops of both water and oil were suddenly absorbed inside the stone and the contact angle was not determinable.

The water-stone contact angle measurements were repeated after the staining and after the paint removal.

Color measurements [60] were performed with a spectrophotometer (mod. CM-700d, Konica Minolta Sensing, Singapore), using CIE Standard illuminant D65 and the target mask $8 \mathrm{~mm}$ in diameter. Ten measurements were performed on each sample area and the instrument was recalibrated to a white calibration cap at the start of each measurement session. The color coordinates were measured on the unprotected surfaces, after the coatings' application, after the staining and after the paint removal.

The colour changes $\left(\Delta E_{\mathrm{ab}}^{*}\right)$ were calculated through the $L^{*} a^{*} b^{*}$ (CIE 1976) system, using Equation (1):

$$
\Delta E_{\mathrm{ab}}^{*}=\left[\left(\Delta L^{*}\right)^{2}+\left(\Delta a^{*}\right)^{2}+\left(\Delta b^{*}\right)^{2}\right]^{1 / 2}
$$

where $L^{*}$ is the lightness/darkness coordinate, $a^{*}$ the red/green coordinate ( $+a^{*}$ indicating red and $-a^{*}$ green), and $b^{*}$ the yellow/blue coordinate ( $+b^{*}$ indicating yellow and $-b^{*}$ blue).

All the colour variations were determined by the comparison with the untreated surfaces, using the averaged values of $L^{*}, a^{*}$, and $b^{*}$ for each sample.

The residual stain (RS) after cleaning was evaluated as a percentage by Equation (2):

$$
\mathrm{RS}=\left[\left(\Delta E_{\mathrm{ab}}^{*}\right) \mathrm{c} /\left(\Delta E_{\mathrm{ab}}^{*}\right) \mathrm{s}\right] \times 100 \%
$$

where $\left(\Delta E_{\mathrm{ab}}^{*}\right) \mathrm{c}$ is the colour variation of the cleaned surfaces and $\left(\Delta E_{\mathrm{ab}}^{*}\right) \mathrm{s}$ is the colour variation of the stained surfaces.

In addition, the efficacy of the cleaning procedure, as compared with the unprotected surfaces, was evaluated by Equation (3):

$$
\text { Relative Efficacy } \%=\left[\left(\mathrm{RS}_{\mathrm{u}}-\mathrm{RS}_{\mathrm{t}}\right) / \mathrm{RS}_{\mathrm{u}}\right] \times 100 \%
$$

where: $\mathrm{RS}_{\mathrm{u}}$ and $\mathrm{RS}_{\mathrm{t}}$ are the residual stain values, as defined in Equation (2), for the unprotected and protected surfaces, respectively.

The stained surfaces were examined under a binocular stereomicroscope (Stemi SV11, Zeiss, Oberkochen, Germany) at magnifications of up to $100 \times$. 


\section{Results and Discussion}

\subsection{Assessment of Basic Prerequisite for Antigraffiti Protection}

The products used as an anti-graffiti barrier typically have a low surface energy at interface, which results in minimizing the contact with the applied paints or inks mainly because the protected surfaces become water and oil repellent. Therefore, treatments able to give good hydrophobicity and oleophobicity to the surfaces are assumed to act as effective systems of graffiti protection [45].

In our case, after the coating's application, most of the protected stone surfaces were able to repel both water and oil, even if to different extent, as it can be clearly inferred from the observation of images reported in Figure 6. Oleophobicity was not observed only in the case of the SW coating, irrespective of the stone substrate.

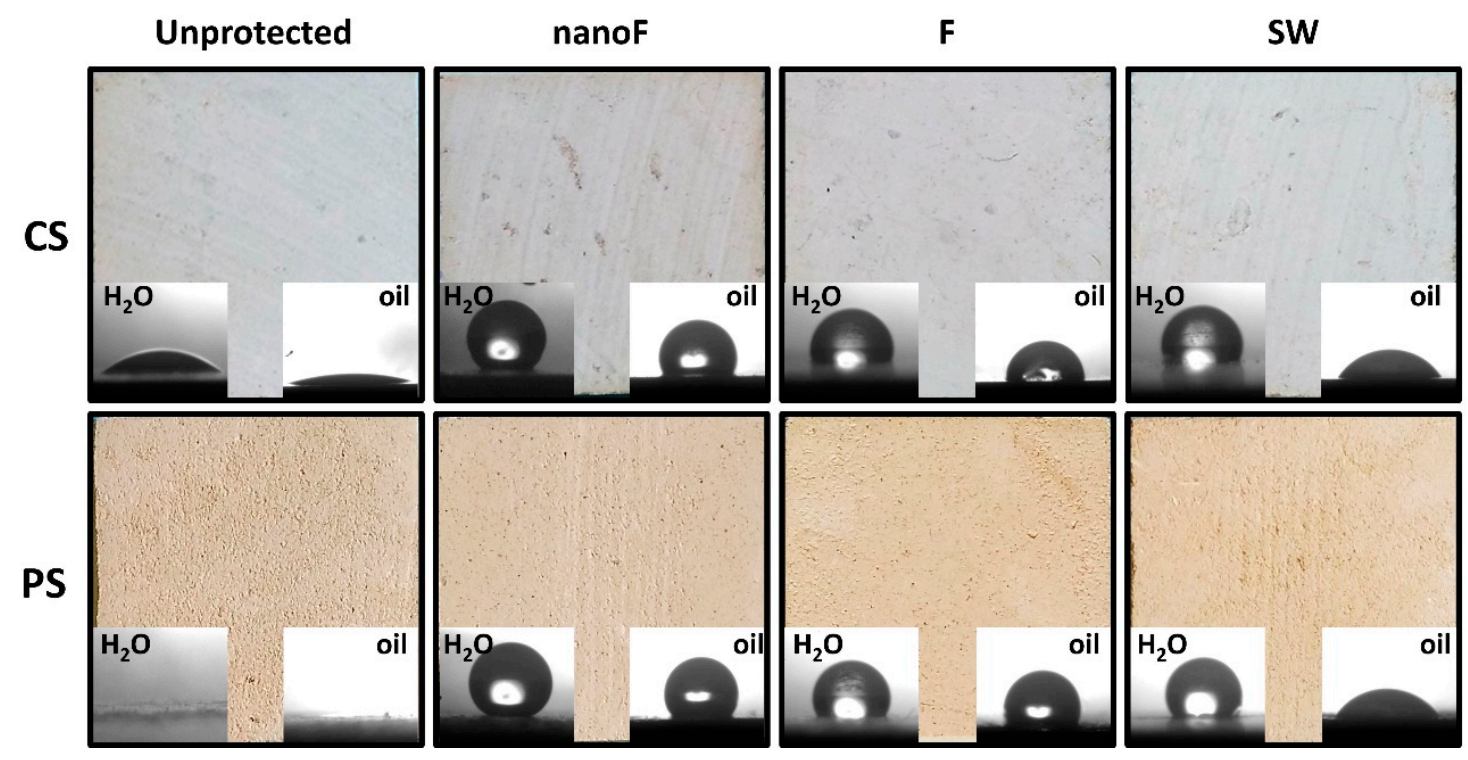

Figure 6. Water and oil droplets on the stone surfaces before and after the protective treatments.

The contact angle values (reported in Table 2) confirmed these surface properties, since water-stone contact angles greater than $90^{\circ}$ are typical of hydrophobic surfaces, while oil-stone contact angles above $70^{\circ}-80^{\circ}$ account for oleophobicity. The lower values measured for oil contact angles with respect to water ones are due to the low surface tension of the oil drops (32 mN/m for olive oil [61], $72 \mathrm{mN} / \mathrm{m}$ for water [57]).

Table 2. Water-stone static contact angle (WCA) and oil-stone static contact angle (OCA), both in degrees, measured on unprotected and protected PS and CS stone surfaces, with the indication of standard deviation.

\begin{tabular}{ccccc}
\hline \multirow{2}{*}{ Samples } & \multicolumn{2}{c}{ CS } & \multicolumn{2}{c}{ PS } \\
\cline { 2 - 5 } & WCA & OCA & WCA & OCA \\
\hline Unprotected & $40 \pm 8$ & $13 \pm 1$ & Not determinable & Not determinable \\
nanoF & $139 \pm 5$ & $114 \pm 1$ & $142 \pm 5$ & $122 \pm 7$ \\
F & $106 \pm 4$ & $93 \pm 4$ & $119 \pm 3$ & $114 \pm 4$ \\
SW & $114 \pm 4$ & $56 \pm 1$ & $122 \pm 4$ & $56 \pm 2$ \\
\hline
\end{tabular}

\subsection{Staining by Spray Paint and Removal}

The superficial distribution of the spray paint on the stone surfaces was observed through the stereomicroscope. The images recorded by the instrument on the different specimens are illustrated in Figure 7. 
Unprotected

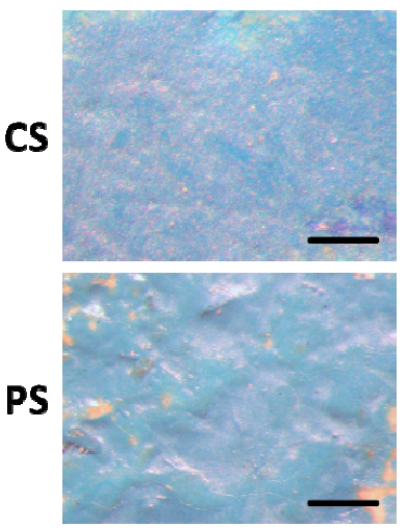

nanoF
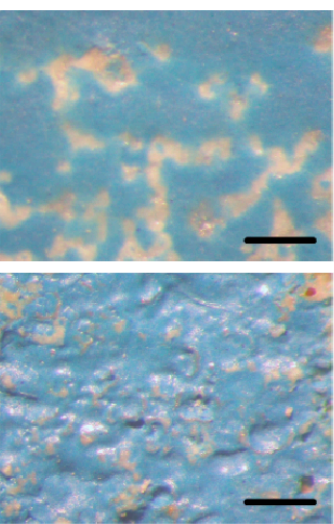

$\mathbf{F}$

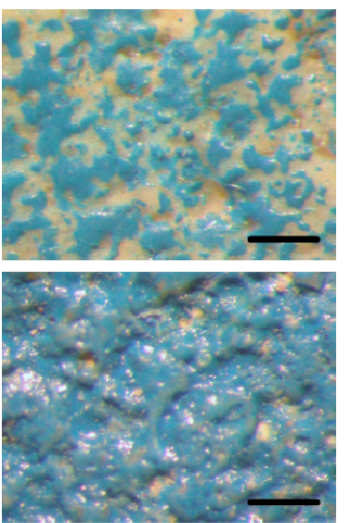

SW

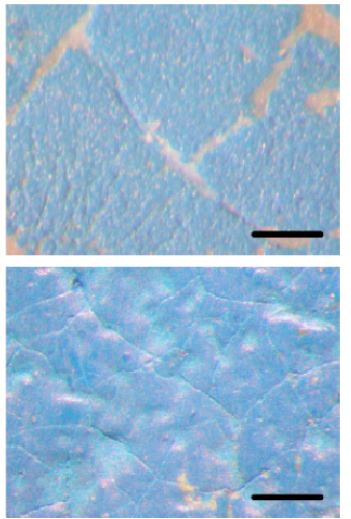

Figure 7. Images taken by the stereomicroscope of the surfaces stained by spray paint: comparison between the protected and unprotected surfaces (CS = compact stone; PS = porous stone). Each scale bar indicates $200 \mu \mathrm{m}$.

In the case of the untreated CS specimens, the paint covered the surface with a uniform film, totally hiding the stone beneath. The presence of protective coatings modified the distribution of the paint. In particular, on the samples treated with SW, the paint coating was affected by cracks due to the drying shrinkage. This latter was likely restrained by the protective layer since cracking was not observed for the unprotected samples. Passing to analyze the specimens treated with nanoF and $\mathrm{F}$ products, the protected surfaces seemed to repel the spray paint, which mainly arranged as separate droplets $[15,25,40,62-64]$, leaving several portions of the stone uncovered. The distribution of the paint affected the color variations, leading to lower differences where the staining agent was repelled, as can be deduced from the data reported in Table 3.

Table 3. Global color difference $\left(\Delta E^{*}{ }_{\mathrm{ab}}\right)$ determined after the staining by spray paint and after the cleaning. For each data set the standard deviation is reported.

\begin{tabular}{ccccc}
\hline \multirow{2}{*}{ Samples } & \multicolumn{2}{c}{ CS } & \multicolumn{2}{c}{ PS } \\
\cline { 2 - 5 } & After Staining & After Removal & After Staining & After Removal \\
\hline Unprotected & $54.53 \pm 0.33$ & $20.19 \pm 2.27$ & $55.39 \pm 1.14$ & $44.58 \pm 4.36$ \\
nanoF & $40.72 \pm 3.56$ & $21.72 \pm 1.85$ & $55.73 \pm 3.96$ & $37.11 \pm 3.35$ \\
F & $45.23 \pm 5.18$ & $5.99 \pm 1.58$ & $56.13 \pm 2.61$ & $13.78 \pm 1.53$ \\
SW & $55.28 \pm 0.44$ & $15.27 \pm 1.95$ & $59.51 \pm 1.99$ & $19.93 \pm 2.96$ \\
\hline
\end{tabular}

The different appearance is also in agreement with the surface oleophobicity. In fact, oil-stone contact angles higher than $90^{\circ}$ were measured only on the nanoF and F treated samples $\left(114^{\circ}\right.$ and $93^{\circ}$, respectively).

Comparable behaviors were observed in the case of PS specimens. A uniform coverage of the stone surface was observed for the unprotected specimens, while a paint coating with cracks was found on the samples coated by SW product. Although less noticeable, uncovered portions of stone and repellence against the paint were observed on the specimens protected by nanoF and F systems, which exhibited the highest oleophobicity. Actually, the high porosity along with the large pore radius likely promoted the accumulation of paint inside the cavities of the porous stone, making less evident the paint repellence. In addition, these effects equalized the color differences and, thus, comparable $\Delta E^{*}{ }_{a b}$ were measured in the stained PS samples (see results reported in Table 3).

The cleaning procedure of this kind of stain with acetone did not give good results. The paint removal was unsuccessful, as already clear to the visual inspection by the naked eye (Figure 8). 


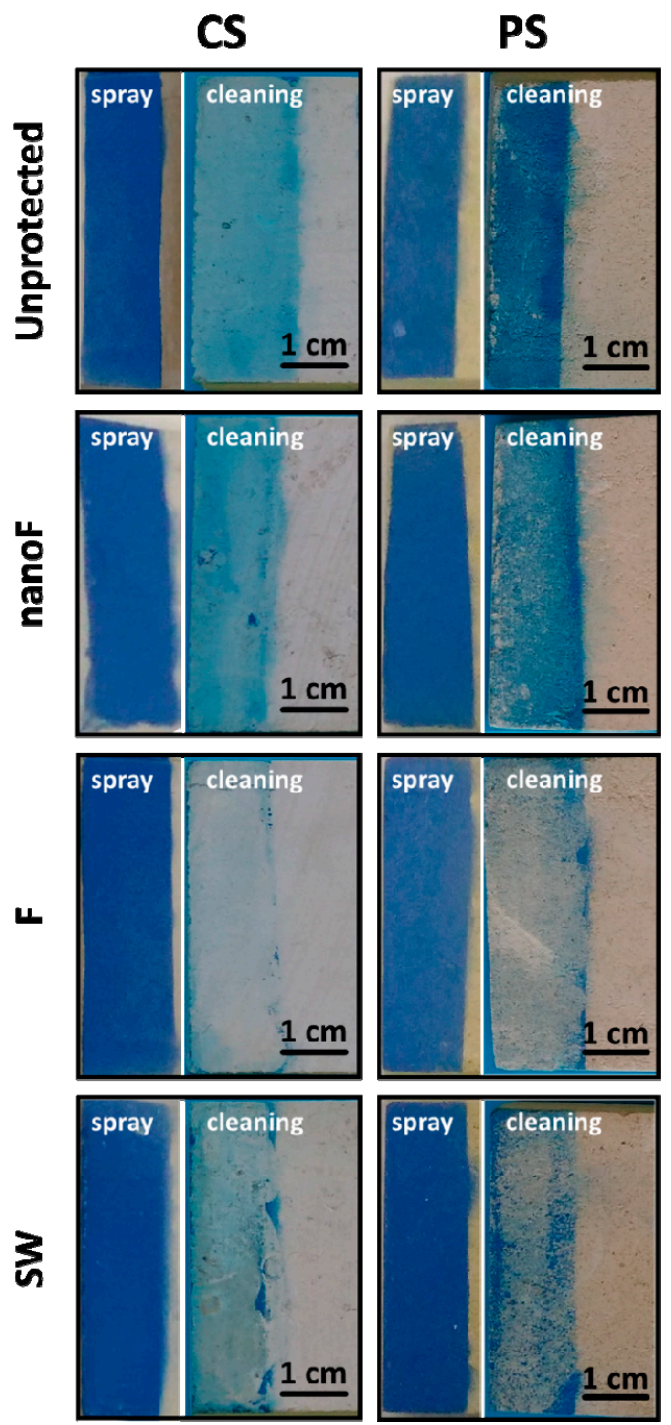

Figure 8. Protected and unprotected stone samples after the staining by spray paint and after the cleaning procedure (CS = compact stone; PS = porous stone); the neat surface is on the right of each image.

To this regard, different methods have been proposed to assess the efficacy of stain removal $[26,65,66]$. A first one was based on the $\Delta E^{*}$ ab measured after the cleaning: values below 5 account for adequate cleaning, while values higher than 10 cannot be accepted; for $\Delta E^{*}$ ab between 5 and 10, the color variations are well visible but still tolerable. In addition, RS can be used to evaluate the removal efficacy $[67,68]$ : values below $10 \%$ can be judged suitable; RS above $20 \%$ means ineffective stain removal; RS values between $10 \%$ and $20 \%$ are not optimal, but tolerable.

Taking into account these classifications, the cleaning with acetone resulted acceptable only for the CS samples treated with the F product, where $\Delta E_{\mathrm{ab}}^{*}$ of approximately 6 CIELAB units and RS of $13 \%$ were measured. Nevertheless, the application of a protective layer was helpful in facilitating the removal of the spray paint. As illustrated in Figure 9a, the RS percentages were always lower than those calculated for the unprotected specimens, except for CS treated with nanoF for which comparable values were found. 


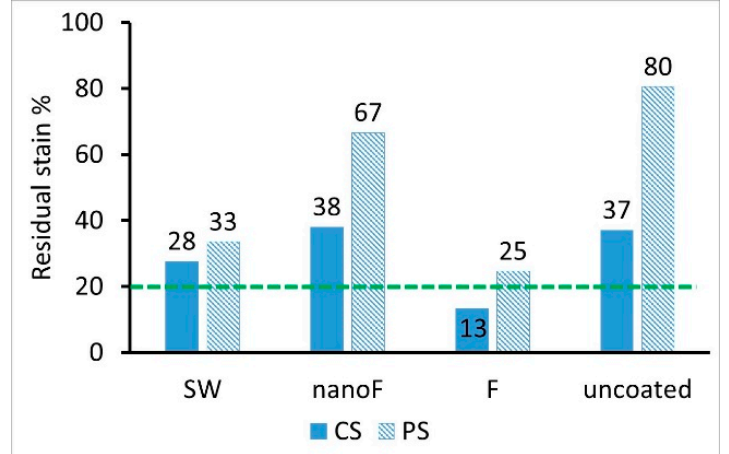

(a)

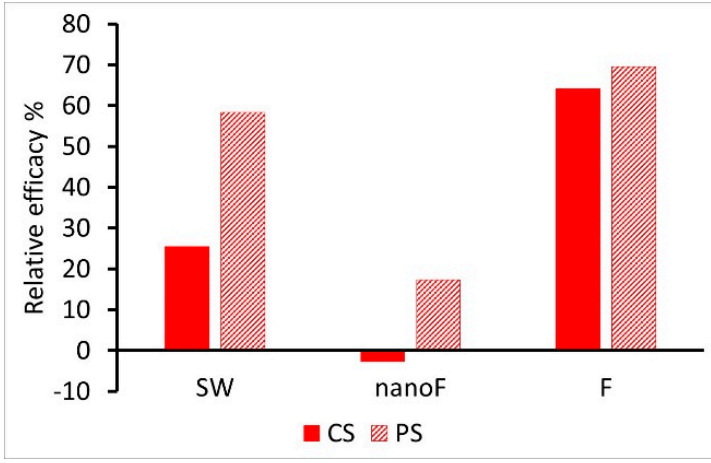

(b)

Figure 9. Evaluation of the spray paint removal: (a) residual stain, as defined in Equation (2), with the green line indicating the acceptable threshold; (b) relative efficacy, as defined in Equation (3).

The relative efficacy, reported in Figure 9b, of the complete procedures (i.e., protection + cleaning) was found to be good in the case of the F-treated specimens; on the other side, it resulted low in the case of the samples where the nanoF coating was applied. Overall, higher values were found for the porous stone, where the paint removal was appreciably more difficult without the presence of a protective layer.

The results of the cleaning seemed to be not related to the observed superficial morphology of the sprayed paint. Neither high oleophobicity nor paint repellence assured good outcomes. On the other hand, as also found in other studies, an observed repellence against the paint did not assure the complete stain removal [69].

The contact angle measurements, whose results are reported in Table 4, were able to supply important information.

Table 4. Water-stone contact angles (in degrees) before and after the protective treatments, after the staining by spray paint, and after the cleaning. For each data set the standard deviation is reported.

\begin{tabular}{cccccc}
\hline Stone Support & Samples & $\begin{array}{c}\text { Before } \\
\text { Treatments }\end{array}$ & $\begin{array}{c}\text { After } \\
\text { Protection }\end{array}$ & $\begin{array}{c}\text { After } \\
\text { Staining }\end{array}$ & $\begin{array}{c}\text { After } \\
\text { Removal }\end{array}$ \\
\hline \multirow{3}{*}{ CS } & Unprotected & $55 \pm 10$ & - & $93 \pm 1$ & $76 \pm 3$ \\
& nanoF & $38 \pm 7$ & $140 \pm 5$ & $98 \pm 3$ & $115 \pm 4$ \\
& F & $44 \pm 7$ & $105 \pm 5$ & $92 \pm 1$ & $116 \pm 4$ \\
& SW & $39 \pm 7$ & $112 \pm 3$ & $101 \pm 4$ & $111 \pm 4$ \\
\hline \multirow{3}{*}{ PS } & Unprotected & n.d. & - & $98 \pm 5$ & $43 \pm 14$ \\
& nanoF & n.d. & $144 \pm 4$ & $106 \pm 7$ & $126 \pm 4$ \\
& F & n.d. & $120 \pm 3$ & $95 \pm 3$ & $128 \pm 4$ \\
& SW & n.d. & $121 \pm 4$ & $101 \pm 4$ & $120 \pm 4$ \\
\hline
\end{tabular}

n.d. $=$ not determinable.

The staining caused a reduction in contact angles in all the samples, with values comparable to those measured on the unprotected surfaces and consistent with the presence of a superficial layer of paint. After the removal with acetone, the contact angle values were still high and measurable. It can be concluded that neither the stain nor the protective coatings were removed, since the hydrophobic character of the surfaces was modified only to a limited extent. An increase in the contact angle values was even observed in the case of the F-treated samples after the cleaning. Other studies report similar behaviors $[45,65,70]$, but the related mechanisms are not clearly explained. A possible explanation for this behavior is the so-called "reverse migration" [71-73]: the used solvent penetrates into the pores of the stone, but migration towards the external surface occurs for evaporation. During these processes, the solvent is able to carry the polymer protective with it. Consequently, greater amounts of product can reach the surface, accounting for a higher hydrophobicity. Even if in fine-porous stone materials (as 
CS) this phenomenon should be restricted [74,75], comparable behaviors were observed irrespective of the porosimetric features of the stone samples. On the other hand, the type of solvent, its tendency to dissolve polymers, and the drying conditions mainly affect the "reverse migration" [75-77]; in addition, the dimensions of the molecules and the solution viscosity can influence the movements of the polymer inside the stone structure.

\subsection{Staining by Felt-Tip Marker and Removal}

The surface appearance of the stone stained by felt-tip marker was investigated through the stereomicroscope, that recorded the images reported in Figure 10.
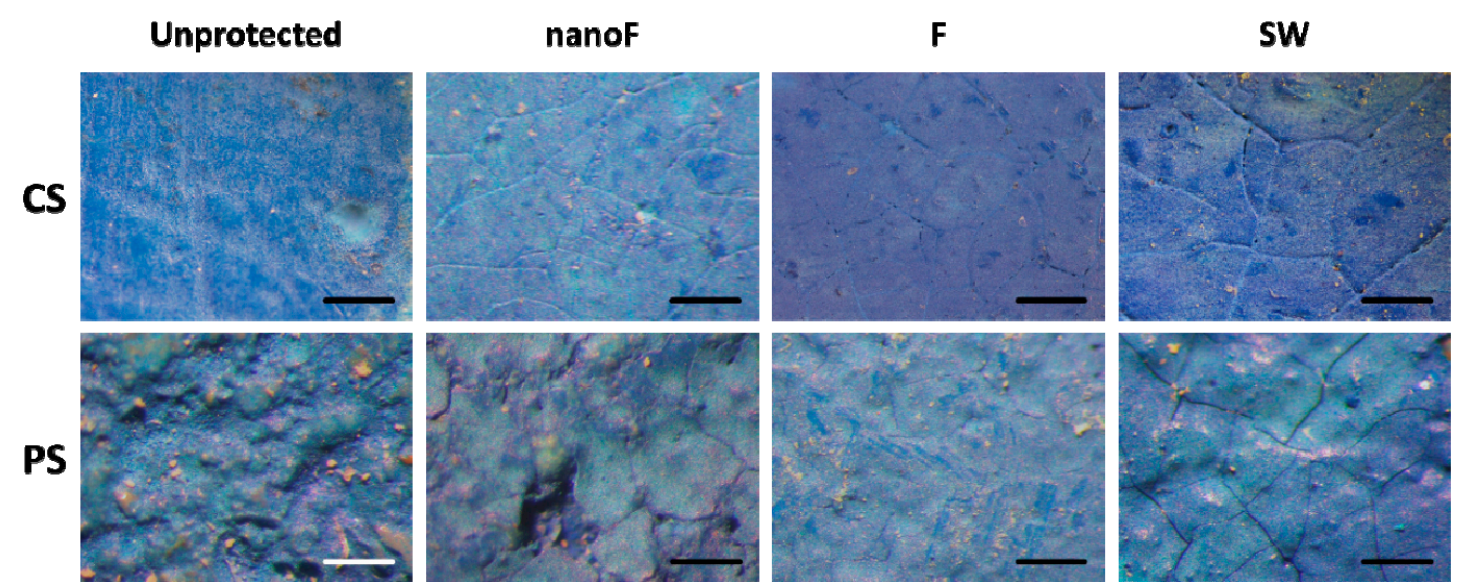

Figure 10. Images taken by the stereomicroscope of the surfaces stained by felt-tip marker: comparison between the protected and unprotected surfaces ( $\mathrm{CS}=$ compact stone; PS = porous stone). Each scale bar indicates $200 \mu \mathrm{m}$.

After the staining, the paint applied by felt-tip marker considerably covered the stone surfaces. In the unprotected samples, the morphological features of the stone were still recognizable and accumulation of the paint in the cavities of the surface was limited. Conversely, in the protected samples, the staining by the marker produced films affected by cracks, as already found in other studies [25]. Additionally, accumulation of stain within the superficial hollows was observed in the PS protected samples.

Dissimilar craquelure patterns were observed on the different specimens. More fractured films were seen in the case of the nanoF and SW treated-samples, regardless of the stone substrate. The paint applied on the F-treated samples displayed sporadic and less evident cracks, instead. Generally speaking, the thickness of any kind of coating influences morphologies and fragment size of cracks $[78,79]$, with a critical value below which no fracturing occurs $[79,80]$. The limited cracking on the F treated-samples suggested a lower thickness of the paint level, probably due to absorption by the protective coating.

The stain applied by the felt-tip marker was not removed with acetone from the stone surfaces; neither the protective coatings improved the cleaning results. In fact, markers are considered the most aggressive staining agents among the methods for graffiti writings. This is mainly due to the fact that their inks contain high percentages of solvents, are very fluid and are, thus, prone to easily fill the pores of the substrate $[81,82]$ already during the staining action.

Following the evaluation detailed in Section 3.2, the stain removal with acetone cannot be judged effective, as also visible to the naked-eye observation (Figure 11). 

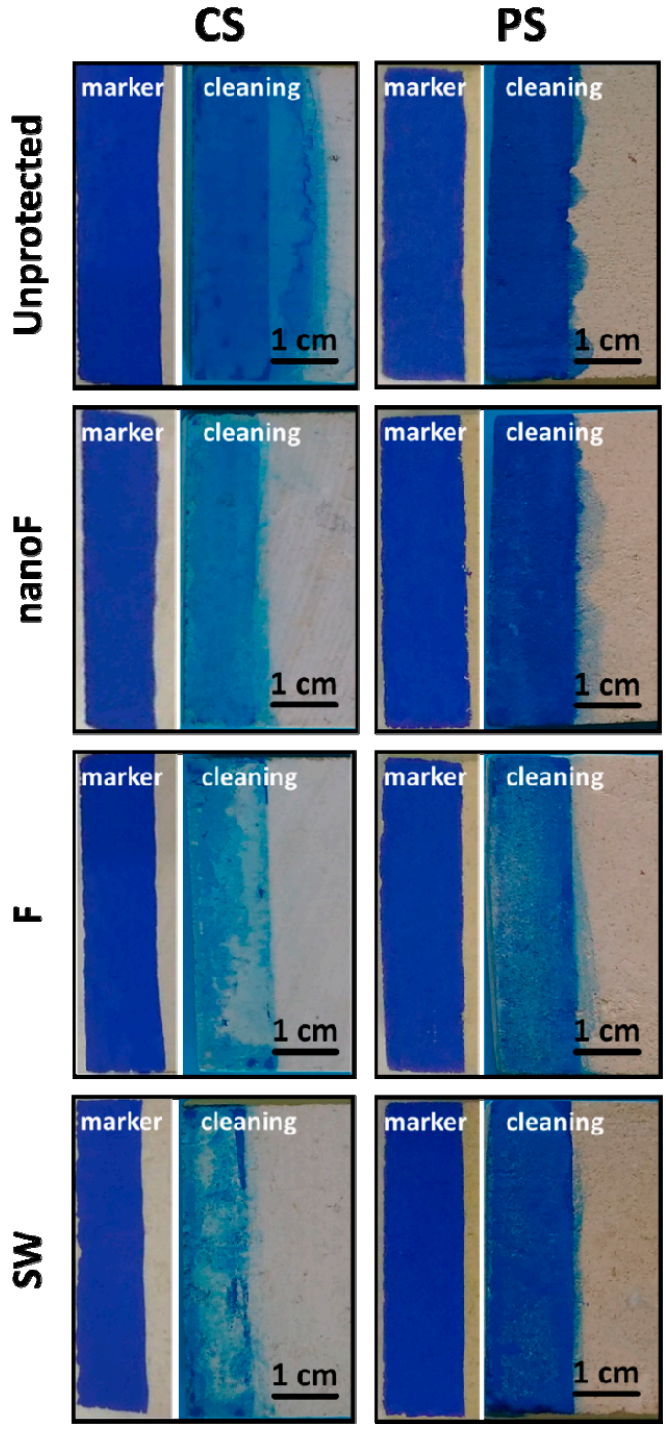

Figure 11. Protected and unprotected stone samples after the staining by felt-tip marker and after the cleaning procedure ( $\mathrm{CS}=$ compact stone; PS = porous stone); the neat surface is on the right of each image.

Accordingly, unacceptable $\Delta E^{*}$ ab were measured after the cleaning of all the samples (see data reported in Table 5), with RS values (Figure 12a) much greater than the tolerable threshold (i.e., 20\%). Only the treatments with the F product yielded low RS percentages.

Table 5. Global color difference $\left(\Delta E^{*}{ }_{\mathrm{ab}}\right)$ determined after the staining by felt-tip marker and after the cleaning. For each data set the standard deviation is reported.

\begin{tabular}{ccccc}
\hline \multirow{2}{*}{ Samples } & \multicolumn{2}{c}{ CS } & \multicolumn{2}{c}{ PS } \\
\cline { 2 - 5 } & After Staining & After Removal & After Staining & After Removal \\
\hline Unprotected & $66.19 \pm 0.37$ & $50.65 \pm 1.98$ & $71.22 \pm 0.70$ & $65.03 \pm 1.93$ \\
nanoF & $58.52 \pm 0.46$ & $23.67 \pm 9.57$ & $70.61 \pm 0.56$ & $66.33 \pm 0.52$ \\
F & $57.95 \pm 1.83$ & $13.35 \pm 4.40$ & $72.88 \pm 0.32$ & $41.23 \pm 12.22$ \\
SW & $48.24 \pm 1.87$ & $19.81 \pm 6.49$ & $72.38 \pm 0.57$ & $62.60 \pm 2.99$ \\
\hline
\end{tabular}




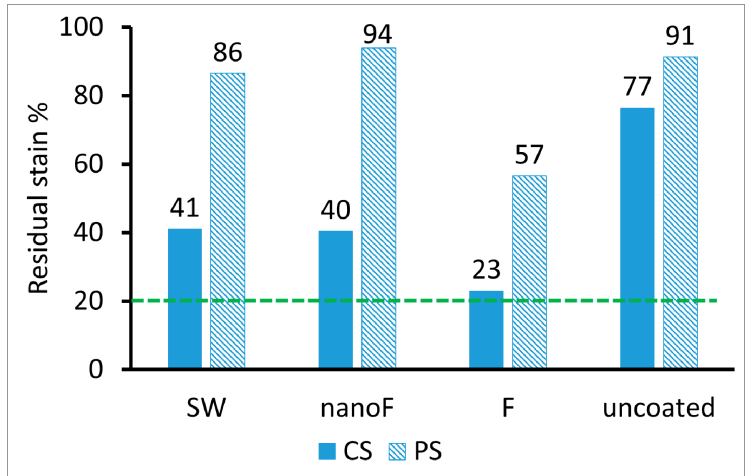

(a)

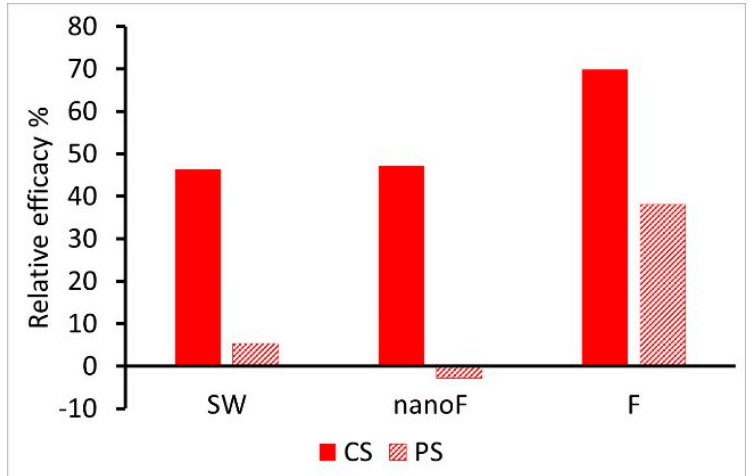

(b)

Figure 12. Evaluation of the felt-tip marker removal: (a) residual stain, as defined in Equation (2), with the green line indicating the acceptable threshold; (b) relative efficacy, as defined in Equation (3).

This result might arise from the embedding of the paint into the protective coating, as previously described. The incorporation of the stain enhanced, even if only slightly, the anti-graffiti effectiveness $[68,83]$. The relative efficacy showed that the cleaning procedure worked better on the CS samples, unlike the spray paint removal, as witnessed by the results presented in Figure 12b.

The correlation of these results with those relative to the oleophobicity of the surfaces did not show a clear trend. Anyway, the most oleophobic surfaces (i.e., that treated with nanoF) were not cleaned to a larger extent.

The results of the contact angle measurements, reported in Table 6 confirmed the failed removal of both paint and protective coating.

Table 6. Water-stone contact angles (in degrees) before and after the protective treatments, after the staining by felt-tip marker, and after the cleaning. For each data set the standard deviation is reported.

\begin{tabular}{cccccc}
\hline Stone Support & Samples & $\begin{array}{c}\text { Before } \\
\text { Treatments }\end{array}$ & $\begin{array}{c}\text { After } \\
\text { Protection }\end{array}$ & $\begin{array}{c}\text { After } \\
\text { Staining }\end{array}$ & $\begin{array}{c}\text { After } \\
\text { Removal }\end{array}$ \\
\hline \multirow{3}{*}{ CS } & Unprotected & $55 \pm 10$ & - & $89 \pm 2$ & $92 \pm 3$ \\
& nanoF & $38 \pm 7$ & $140 \pm 5$ & $80 \pm 3$ & $101 \pm 9$ \\
& F & $44 \pm 7$ & $105 \pm 5$ & $79 \pm 5$ & $106 \pm 2$ \\
& SW & $39 \pm 7$ & $112 \pm 3$ & $80 \pm 3$ & $110 \pm 2$ \\
\hline \multirow{3}{*}{ PS } & Unprotected & n.d. & - & $98 \pm 5$ & $106 \pm 7$ \\
& nanoF & n.d. & $144 \pm 4$ & $83 \pm 13$ & $122 \pm 8$ \\
& F & n.d. & $120 \pm 3$ & $90 \pm 12$ & $117 \pm 4$ \\
& SW & n.d. & $121 \pm 4$ & $70 \pm 12$ & $106 \pm 6$ \\
\hline
\end{tabular}

n.d. = not determinable.

After the staining, contact angles between $70^{\circ}$ and $97^{\circ}$ were measured. Hydrophobicity was recovered on the cleaned samples, but the contact angles remained below the values obtained after the application of the protective treatment. The phenomenon of "reverse migration" can be hypothesized also in these samples. This effect, particularly evident for the unprotected surfaces, where unexpected high contact angles $\left(>90^{\circ}\right)$ were found after the cleaning, was most likely due to transfer of the absorbed paint binder activated by the cleaning solvent towards the surface on the stone. On the other hand, the occurrence of movements of the solvent and the dissolved stain were well visible to the naked-eye, since, during the cleaning, the paint spread beyond the previously stained area (Figures 9 and 11).

\section{Conclusions}

The anti-graffiti behavior of three protective treatments has been tested on compact and porous calcareous stone materials. An experimental formulation, based on fluorine resins and 
$\mathrm{SiO}_{2}$ nano-particles, and two commercial products were applied. The results of cleaning procedures after the staining by spray paint and felt-tip marker were discussed.

The applied products provided surfaces able to repel both water and oil, thus meeting a fundamental requirement for anti-graffiti systems.

The simulation of staining actions gave rise to a distribution of the paints on the surfaces dependent on the presence and nature of the protective coating. Uniform films covering the surface, totally hiding the stone beneath, were observed in the case of untreated specimens. In most of the protected surfaces, the paint film was affected by cracks due to its shrinkage upon drying. The protective coatings restrained this cracking, which, in fact, was not noticed for the unprotected samples. Evidence of repellence against the stain was optically observed only after the application of the spray paint. In accordance with the higher surface oleophobicity, separate droplets of paint, together with portions of uncovered stone, were seen on the nanoF and F treated-samples. The morphological and porosimetric features of the stone seemed influence the paint spreading on the surface to a limited extent.

Although the removal with acetone affected the paint layer to different degrees, this procedure was not able to supply good results. The residual stain percentage was always above the threshold limit of $20 \%$, except for the compact stone surfaces coated with F product and stained by spray paint. The paint removal was more difficult on the highly porous stone, where greater values of residual stain were found. The presence of protective coatings enhanced the spray paint removal On the contrary, the stain from the felt-tip marker was not removed even where protective coatings were applied, thus confirming a stronger action of this graffiti agent. The relative efficacy of the cleaning was influenced by the type of staining agent rather than the porosity of the substrate. In both cases, the proved hydrophobicity and oleophobicity, as well as the observed paint repellence, did not provide positive outcome of the cleaning.

The protective coatings were not eliminated from the surfaces during the cleaning; rather, the polymer protectives migrated into the porous structure of the stone under the effect of solvent evaporation. In fact, as a consequence of greater amounts of hydrophobic product moved at the surface, increased contact angle values were measured after the cleaning with acetone. This result further supports the inefficacy of the cleaning procedure with neat acetone. The unconfined solvent can spread the dissolved paint into the pores of the substrate. In this case, the stain may affect also the internal part of the stone materials making almost impossible an effective cleaning.

In conclusion, although hydrophobicity and oleophobicity are considered basic requirements of anti-graffiti coatings, these surface properties do not assure good removal of vandalic writings. The success of the anti-graffiti action depends on the applied staining agent, on the used cleaning procedure and, to a more limited extent, on the affected substrate. Therefore, the actual performance of an anti-graffiti system cannot be deduced from the coating's properties but the effectiveness needs to be assessed in the specific applicative conditions.

Further investigations are in progress to verify the anti-graffiti efficacy under additional cleaning methods, specifically, chemical cleaners in gel matrices; the coatings' performance after the application of higher amounts of product is another ongoing evaluation.

Author Contributions: Conceptualization, M.L. and M.F.; Formal Analysis, M.L., M.M. and M.F.; Investigation, M.M., M.P. and A.M.; Writing-Review and Editing, M.L. and M.F.; Supervision, M.F.

Funding: This research received no external funding.

Acknowledgments: The work is the outcome of a scientific collaboration carried out with Kimia Company (Perugia, Italy), which supplied the experimental (nanoF) product under investigation. To this regards, the Authors wish to thank Assorestauro Association, and the Advisor of the Board Arch. Cristina Caiulo, for the scientific networking created between University of Salento and Kimia Company. Thanks are also due to Davide Melica for the realization of the thin cross sections.

Conflicts of Interest: The authors declare no conflict of interest. 


\section{References}

1. GRAFFOLUTION, Awareness and Prevention Solutions against Graffiti Vandalism in Public Areas and Transport. SSP (Policy Oriented Research) of the Seventh European Programme of the European Commission. FP7-SEC-2013-1. 2016. Available online: http://project.graffolution.eu/po/ (accessed on 26 September 2019).

2. Macchia, A.; Ruffolo, S.A.; Rivaroli, L.; Malagodi, M.; Licchelli, M.; Rovella, N.; Randazzo, L.; La Russa, M.F. Comparative study of protective coatings for the conservation of Urban Art. J. Cult. Herit. 2019, in press. [CrossRef]

3. Bosi, A.; Ciccola, A.; Serafini, I.; Guiso, M.; Ripanti, F.; Postorino, P.; Curini, R.; Bianco, A. Street art graffiti: Discovering their composition and alteration by FTIR and micro-Raman spectroscopy. Spectrochim. Acta A Mol. Biomol. Spectrosc. 2020, 225, 117474. [CrossRef] [PubMed]

4. Sanmartín, P.; Cappitelli, F. Evaluation of accelerated ageing tests for metallic and non-metallic graffiti paints applied to stone. Coatings 2017, 7, 180. [CrossRef]

5. Dionísio, A.; Ribeiro, T. When graffiti is not art: The damage of alkyd sprays on calcareous stones employed in Cultural Heritage. In Cultural Heritage: Protection, Developments and International Perspectives (Focus on Civilizations and Cultures); Nova Science Publishers: Hauppauge, NY, USA, 2013; pp. 279-291, ISBN 978-1-62808-822-9.

6. Gomes, V.; Dionísio, A.; Pozo-Antonio, J.S. Conservation strategies against graffiti vandalism on Cultural Heritage stones: Protective coatings and cleaning methods. Prog. Org. Coat. 2017, 113, 90-109. [CrossRef]

7. Sanmartín, P.; Cappitelli, F.; Mitchell, R. Current methods of graffiti removal: A review. Constr. Build. Mater. 2014, 71, 363-374. [CrossRef]

8. Rivas, T.; Pozo, S.; Fiorucci, M.P.; López, A.J.; Ramil, A. Nd: YVO4 laser removal of graffiti from granite. Influence of paint and rock properties on cleaning efficacy. Appl. Surf. Sci. 2012, 263, 563-572. [CrossRef]

9. Samolik, S.; Walczak, M.; Plotek, M.; Sarzynski, A.; Pluska, I.; Marczak, J. Investigation into the removal of graffiti on mineral supports: Comparison of nanosecond Nd: YAG laser cleaning with traditional mechanical and chemical methods. Stud. Conserv. 2015, 60, S58-S64. [CrossRef]

10. Rossi, S.; Fedel, M.; Petrolli, S.; Deflorian, F. Behaviour of different removers on permanent anti-graffiti organic coatings. J. Build. Eng. 2016, 5, 104-113. [CrossRef]

11. Pozo-Antonio, J.S.; Rivas, T.; Fiorucci, M.P.; López, A.J.; Ramil, A. Effectiveness and harmfulness evaluation of graffiti cleaning by mechanical, chemical and laser procedures on granite. Microchem. J. 2016, 125, 1-9. [CrossRef]

12. Sanmartín, P.; Bosch-Roig, P. Biocleaning to remove graffiti: A real possibility? Advances towards a complete protocol of action. Coatings 2019, 9, 104. [CrossRef]

13. Germinario, G.; van der Werf, I.D.; Palazzo, G.; Regidor Ros, J.L.; Montes-Estelles, R.M.; Sabbatini, L. Bioremoval of marker pen inks by exploiting lipase hydrolysis. Prog. Org. Coat. 2017, 110, $162-171$. [CrossRef]

14. García, O.; Malaga, K. Definition of the procedure to determine the suitability and durability of an anti-graffiti product for application on cultural heritage porous materials. J. Cult. Herit. 2012, 13, 77-82. [CrossRef]

15. Licchelli, M.; Marzolla, S.J.; Poggi, A.; Zanchi, C. Crosslinked fluorinated polyurethanes for the protection of stone surfaces from graffiti. J. Cult. Herit. 2011, 12, 34-43. [CrossRef]

16. Liu, H.; Gao, L.; Shang, Q.; Xiao, G. Preparation and characterization of polyurethane clearcoats and investigation into their antigraffiti property. J. Coat. Technol. Res. 2013, 10, 775-784. [CrossRef]

17. Rabea, A.M.; Mohseni, M.; Mirabedini, S.M.; Tabatabaei, M.H. Surface analysis and anti-graffiti behavior of a weathered polyurethane-based coating embedded with hydrophobic nano silica. Appl. Surf. Sci. 2012, 258, 4391-4396. [CrossRef]

18. Manvi, G.N.; Singh, A.R.; Jagtap, R.N.; Kothari, D.C. Isocyanurate based fluorinated polyurethane dispersion for anti-graffiti coatings. Prog. Org. Coat. 2012, 75, 139-146. [CrossRef]

19. Carmona-Quiroga, P.M.; Rubio, J.; Sánchez, M.J.; Martínez-Ramírez, S.; Blanco-Varela, M.T. Surface dispersive energy determined with IGC-ID in anti-graffiti-coated building materials. Prog. Org. Coat. 2011, 71, $207-212$. [CrossRef]

20. García, O.; Rz-Maribona, I.; Gardei, A.; Riedl, M.; Vanhellemont, Y.; Santarelli, M.L.; Suput, J.S. Comparative study of the variation of the hydric properties and aspect of natural stone and brick after the application of 4 types of anti-graffiti. Mater. Constr. 2010, 60, 69-82. [CrossRef] 
21. Carmona-Quiroga, P.M.; Jacobs, R.M.J.; Martínez-Ramírez, S.; Viles, H.A. Durability of anti-graffiti coatings on stone: Natural vs accelerated weathering. PLoS ONE 2017, 12, e0172347. [CrossRef]

22. Kharitonov, A.P.; Simbirtseva, G.V.; Nazarov, V.G.; Stolyarov, V.P.; Dubois, M.; Peyroux, J. Enhanced anti-graffiti or adhesion properties of polymers using versatile combination of fluorination and polymer grafting. Prog. Org. Coat. 2015, 88, 127-136. [CrossRef]

23. Esposito Corcione, C.; De Simone, N.; Santarelli, M.L.; Frigione, M. Protective properties and durability characteristics of experimental and commercial organic coatings for the preservation of porous stone. Prog. Org. Coat. 2017, 103, 193-203. [CrossRef]

24. Heinisch, M.; Miricescu, D. Innovative industrial technologies for preventive anti-graffiti coating. In MATEC Web of Conferenes; EDP Sciences: Les Ulis, France, 2017; Volume 121, p. 03009.

25. Licchelli, M.; Malagodi, M.; Weththimuni, M.; Zanchi, C. Anti-Graffiti nanocomposite materials for surface protection of a very porous stone. Appl. Phys. A 2014, 116, 1525-1539. [CrossRef]

26. Moura, A.; Flores-Colen, I.; De Brito, J. Study of the effect of three anti-graffiti products on the physical properties of different substrates. Constr. Build. Mater. 2016, 107, 157-164. [CrossRef]

27. Fedel, M.; Rossi, S.; Deflorian, F. Polymethyl (hydro)/polydimethylsilazane-derived coatings applied on AA1050: Effect of the dilution in butyl acetate on the structural and electrochemical properties. J. Coat. Technol. Res. 2019, 16, 1013-1019. [CrossRef]

28. Melquiades, F.L.; Appoloni, C.R.; Andrello, A.C.; Spagnuolo, E. Non-Destructive analytical techniques for the evaluation of cleaning and protection processes on white marble surfaces. J. Cult. Herit. 2019, 37, 54-62. [CrossRef]

29. Frigione, M.; Lettieri, M. Novel attribute of organic-inorganic hybrid coatings for protection and preservation of materials (stone and wood) belonging to cultural heritage. Coatings 2018, 8, 319. [CrossRef]

30. Kronlund, D.; Lindén, M.; Smått, J.-H. A sprayable protective coating for marble with water-repellent and anti-graffiti properties. Prog. Org. Coat. 2016, 101, 359-366. [CrossRef]

31. Bayer, S.I. On the durability and wear resistance of transparent superhydrophobic coatings. Coatings 2017, 7, 12. [CrossRef]

32. Bormashenko, E. Physics of solid-liquid interfaces: From the Young equation to the superhydrophobicity. Low Temp. Phys. 2016, 42, 622-635. [CrossRef]

33. Simpson, J.T.; Hunter, S.R.; Aytug, T. Superhydrophobic materials and coatings: A review. Rep. Prog. Phys. 2015, 78, 086501. [CrossRef]

34. Milionis, A.; Loth, E.; Bayer, I.S. Recent advances in the mechanical durability of superhydrophobic materials. Adv. Colloid Interface Sci. 2016, 229, 57-79. [CrossRef] [PubMed]

35. Cohen, N.; Dotan, A.; Dodiuk, H.; Kenig, S. Superhydrophobic coatings and their durability. Mater. Manuf. Process. 2016, 31, 1143-1155. [CrossRef]

36. Manoudis, P.N.; Tsakalof, A.; Karapanagiotis, I.; Zuburtikudis, I.; Panayiotou, C. Fabrication of super-hydrophobic surfaces for enhanced stone protection. Surf. Coat. Technol. 2009, 203, 1322-1328. [CrossRef]

37. Milionis, A.; Bayer, I.S.; Loth, E. Recent advances in oil-repellent surfaces. Int. Mater. Rev. 2016, 61, 101-126. [CrossRef]

38. Hosseini, M.; Karapanagiotis, I. (Eds.) Advanced Materials for the Conservation of Stone; Springer: Cham, Switzerland, 2018; ISBN 978-3-319-72260-3.

39. Godeau, G.; Guittard, F.; Darmanin, T. Surfaces bearing fluorinated nucleoperfluorolipids for potential anti-graffiti surface properties. Coatings 2017, 7, 220. [CrossRef]

40. Haas, K.-H.; Amberg-Schwab, S.; Rose, K. Functionalized coating materials based on inorganic-organic polymers. Thin Solid Film. 1999, 351, 198-203. [CrossRef]

41. Badila, M.; Kohlmayr, M.; Zikulnig-Rusch, E.M.; Dolezel-Horwath, E.; Kandelbauer, A. Improving the cleanability of melamine-formaldehyde-based decorative laminates. J. Appl. Polym. Sci. 2014, 131, 40964. [CrossRef]

42. Xu, F.; Li, X.; Li, Y.; Sun, J. Oil-repellent antifogging films with water-enabled functional and structural healing ability. ACS Appl. Mater. Interfaces 2017, 9, 27955-27963. [CrossRef]

43. Carmona-Quiroga, P.M.; Martínez-Ramírez, S.; Sánchez-Cortés, S.; Oujja, M.; Castillejo, M.; Blanco-Varela, M.T. Effectiveness of antigraffiti treatments in connection with penetration depth determined by different techniques. J. Cult. Herit. 2010, 11, 297-303. [CrossRef] 
44. Khan, F.; Khan, A.; Tuhin, M.O.; Rabnawaz, M.; Li, Z.; Naveed, M. A novel dual-layer approach towards omniphobic polyurethane coatings. RSC Adv. 2019, 9, 26703-26711. [CrossRef]

45. Malaga, K.; Mueller, U. Relevance of hydrophobic and oleophobic properties of antigraffiti systems on their cleaning efficiency on concrete and stone surfaces. J. Mater. Civ. Eng. 2013, 25, 755-762. [CrossRef]

46. Scheerder, J.; Visscher, N.; Nabuurs, T.; Overbeek, A. Novel, water-based fluorinated polymers with excellent antigraffiti properties. J. Coat. Technol. Res. 2005, 2, 617-625. [CrossRef]

47. Lettieri, M.; Masieri, M.; Morelli, A.; Pipoli, M.; Frigione, M. Oleo/hydrophobic coatings containing nano-particles for the protection of stone materials having different porosity. Coatings 2018, 8, 429. [CrossRef]

48. Bugani, S.; Camaiti, M.; Morselli, L.; Van de Casteele, E.; Janssens, K. Investigation on porosity changes of Lecce stone due to conservation treatments by means of X-ray nano- and improved micro-computed tomography: Preliminary results. X-Ray Spectrom. 2007, 36, 316-320. [CrossRef]

49. Föllmi, K.B.; Hofmann, H.; Chiaradia, M.; de Kaenel, E.; Frijia, G.; Parente, M. Miocene phosphate-rich sediments in Salento (southern Italy). Sediment. Geol. 2015, 327, 55-71. [CrossRef]

50. Tiano, P.; Accolla, P.; Tomaselli, L. Phototrophic biodeteriogens on lithoid surfaces: An ecological study. Microb. Ecol. 1995, 29, 299-309. [CrossRef] [PubMed]

51. Dunham, R.J. Classification of carbonate rocks according to depositional textures. AAPG Mem. 1962, 1, 108-121.

52. NORMAL Rec. 4/80 Distribuzione del Volume dei Pori in Funzione del Loro Diametro; CNR/ICR: Rome, Italy, 1980.

53. UNI 10921. Beni Culturali Materiali Lapidei Naturali ed Artificiali_Prodotti Idrorepellenti-Applicazione su Provini e Determinazione in Laboratorio Delle Loro Caratteristiche; Ente Italiano di normazione: Milan, Italy, 2001.

54. ASTM D 6578. Standard Practice for Determination of Graffiti Resistance; ASTM International: West Conshohocken, PA, USA, 2000.

55. Baglioni, M.; Poggi, G.; Jaidar Benavides, Y.; Martínez Camacho, F.; Giorgi, R.; Baglioni, P. Nanostructured fluids for the removal of graffiti-A survey on 17 commercial spray-can paints. J. Cult. Herit. 2018, 34, 218-226. [CrossRef]

56. EN 15802. Conservation of Cultural Property-Test Methods-Determination of Static Contact Angle; CEN (European Committee for Standardization): Brussels, Belgium, 2010.

57. Aslanidou, D.; Karapanagiotis, I.; Panayiotou, C. Tuning the wetting properties of siloxane-nanoparticle coatings to induce superhydrophobicity and superoleophobicity for stone protection. Mater. Des. 2016, 108, 736-744. [CrossRef]

58. Facio, D.S.; Carrascosa, L.A.M.; Mosquera, M.J. Producing lasting amphiphobic building surfaces with self-cleaning properties. Nanotechnology 2017, 28, 265601. [CrossRef]

59. Aslanidou, D.; Karapanagiotis, I.; Lampakis, D. Waterborne superhydrophobic and superoleophobic coatings for the protection of marble and sandstone. Materials 2018, 11, 585. [CrossRef] [PubMed]

60. EN 15886. Conservation of Cultural Property-Test Methods-Colour Measurement of Surfaces; CEN (European Committee for Standardization): Brussels, Belgium, 2010.

61. Sahasrabudhe, S.N.; Rodriguez-Martinez, V.; O’Meara, M.; Farkas, B.E. Density, viscosity, and surface tension of five vegetable oils at elevated temperatures: Measurement and modeling. Int. J. Food Prop. 2017, 20, 1965-1981. [CrossRef]

62. Rabea, A.M.; Mirabedini, S.M.; Mohseni, M. Investigating the surface properties of polyurethane based anti-graffiti coatings against UV exposure. J. Appl. Polym. Sci. 2012, 124, 3082-3091. [CrossRef]

63. Shang, B.; Chen, M.; Wu, L. One-step synthesis of statically amphiphilic/dynamically amphiphobic fluoride-free transparent coatings. ACS Appl. Mater. Interfaces 2018, 10, 41824-41830. [CrossRef] [PubMed]

64. Zhong, X.; Hu, H.; Yang, L.; Sheng, J.; Fu, H. Robust hyperbranched polyester-based anti-smudge coatings for self-cleaning, anti-graffiti, and chemical shielding. ACS Appl. Mater. Interfaces 2019, 11, 14305-14312. [CrossRef] [PubMed]

65. Carvalhão, M.; Dionísio, A. Evaluation of mechanical soft-abrasive blasting and chemical cleaning methods on alkyd-paint graffiti made on calcareous stones. J. Cult. Herit. 2015, 16, 579-590. [CrossRef]

66. Gherardi, F.; Colombo, A.; D’Arienzo, M.; Di Credico, B.; Goidanich, S.; Morazzoni, F.; Simonutti, R.; Toniolo, L. Efficient self-cleaning treatments for built heritage based on highly photo-active and well-dispersible $\mathrm{TiO}_{2}$ nanocrystals. Microchem. J. 2016, 126, 54-62. [CrossRef]

67. Gomes, V.; Dionísio, A.; Pozo-Antonio, J.S. The influence of the $\mathrm{SO}_{2}$ ageing on the graffiti cleaning effectiveness with chemical procedures on a granite substrate. Sci. Total Environ. 2018, 625, 233-245. [CrossRef] 
68. Masieri, M.; Lettieri, M. Influence of the distribution of a spray paint on the efficacy of anti-graffiti coatings on a highly porous natural stone material. Coatings 2017, 7, 18. [CrossRef]

69. Tarnowski, A.; Zhang, X.; Mcnamara, C.; Martin, S.; Mitchell, R. Biodeterioration and performance of anti-graffiti coatings on sandstone and marble. J. Can. Assoc. Conserv. J CAC 2007, 32, 3-16.

70. Pozo-Antonio, J.S.; Rivas, T.; Jacobs, R.M.J.; Viles, H.A.; Carmona-Quiroga, P.M. Effectiveness of commercial anti-graffiti treatments in two granites of different texture and mineralogy. Prog. Org. Coat. 2018, 116, 70-82. [CrossRef]

71. Poli, T.; Toniolo, L. The challenge of protecting monuments from atmospheric attack. In Fracture and Failure of Natural Building Stones: Applications in the Restoration of Ancient Monuments; Kourkoulis, S.K., Ed.; Springer Netherlands: Dordrecht, The Netherlands, 2006; pp. 553-563, ISBN 978-1-4020-5077-0.

72. Selwitz, C. Epoxy Resins in Stone Conservation; Getty Publications: Marina del Rey, CA, USA, 1992; Volume 7, ISBN 0-89236-238-3.

73. Sena da Fonseca, B.; Piçarra, S.; Ferreira Pinto, A.P.; Ferreira, M.J.; Montemor, M.F. TEOS-based consolidants for carbonate stones: The role of N1-(3-trimethoxysilylpropyl)diethylenetriamine. New J. Chem. 2017, 41, 2458-2467. [CrossRef]

74. Borsoi, G.; Lubelli, B.; van Hees, R.; Veiga, R.; Silva, A.S.; Colla, L.; Fedele, L.; Tomasin, P. Effect of solvent on nanolime transport within limestone: How to improve in-depth deposition. Colloids Surf. Physicochem. Eng. Asp. 2016, 497, 171-181. [CrossRef]

75. Domaslowski, W. The mechanism of polymer migration in porous stones. Wien. Ber. Über Nat. Kunst 1988, 4 , 402-425.

76. Hansen, E.F.; Lowinger, R.; Sadoff, E. Consolidation of porous paint in a vapor-saturated atmosphere a technique for minimizing changes in the appearance of powdering, matte paint. J. Am. Inst. Conserv. 1993, 32, 1-14.

77. Sena da Fonseca, B.; Piçarra, S.; Pinto, A.P.; Montemor, M.d.F. Polyethylene glycol oligomers as siloxane modificators in consolidation of carbonate stones. Pure Appl. Chem. 2016, 88, 1117. [CrossRef]

78. Giorgiutti-Dauphiné, F.; Pauchard, L. Painting cracks: A way to investigate the pictorial matter. J. Appl. Phys. 2016, 120, 065107. [CrossRef]

79. Krzemień, L.; Łukomski, M.; Bratasz, Ł.; Kozłowski, R.; Mecklenburg, M.F. Mechanism of craquelure pattern formation on panel paintings. Stud. Conserv. 2016, 61, 324-330. [CrossRef]

80. Atkinson, A.; Guppy, R.M. Mechanical stability of sol-gel films. J. Mater. Sci. 1991, 26, 3869-3873. [CrossRef]

81. Moura, A.R.; Flores-Colen, I.; de Brito, J. Anti-Graffiti products for porous surfaces. An overview. In Proceedings of the Hydrophobe VII 7th International Conference on Water Repellent Treatment and Protective Surface Technology for Building Materials, LNEC (Laboratório Nacional de Engenharia Civil), Lisbon, Portugal, 11-12 September 2014; pp. 225-233.

82. Moretti, P.; Germinario, G.; Doherty, B.; van der Werf, I.D.; Sabbatini, L.; Mirabile, A.; Sgamellotti, A.; Miliani, C. Disclosing the composition of historical commercial felt-tip pens used in art by integrated vibrational spectroscopy and pyrolysis-gas chromatography/mass spectrometry. J. Cult. Herit. 2019, 35, 242-253. [CrossRef]

83. Lettieri, M.; Masieri, M. Surface characterization and effectiveness evaluation of anti-graffiti coatings on highly porous stone materials. Appl. Surf. Sci. 2014, 288, 466-477. [CrossRef]

(C) 2019 by the authors. Licensee MDPI, Basel, Switzerland. This article is an open access article distributed under the terms and conditions of the Creative Commons Attribution (CC BY) license (http://creativecommons.org/licenses/by/4.0/). 